\title{
Teaching optics in a multi-disciplinary curriculum: experience from optometry programs
}

\section{Vasudevan Lakshminarayanan}

Vasudevan Lakshminarayanan, "Teaching optics in a multi-disciplinary curriculum: experience from optometry programs," Proc. SPIE 9665, Tenth International Topical Meeting on Education and Training in Optics and Photonics, 96651D (3 June 2007); doi: 10.1117/12.2207538

SDIE Event: Tenth International Topical Meeting on Education and Training in Optics and Photonics, 2007, Ottawa, Ontario, Canada 


\title{
Teaching Optics in a Multi-Disciplinary Curriculum: Experience From Optometry Programs
}

\author{
Vasudevan Lakshminarayanan \\ School of Optometry and Depts. of Physics and Electrical Engineering University of Waterloo, 200 University Avenue West, \\ Waterloo, Ontario, Canada N2L3G1. Email: vengu@uwaterloo.ca; Phone: 519.888 .4567 ext.38167
}

\begin{abstract}
The Optometry program in Schools and Colleges of Optometry leads to a Doctor of Optometry (OD) degree in north America and is usually a post-baccalaureate course of study of four years duration. Historically Optometry developed out of Physics and/or applied optics programs. Optics, and more specifically, geometric optics and it's applications to the human eye plays a significant role in the education of an optometrist. In addition, optometrists are trained in physical optics as well as in radiometry/photometry. Considering the fact that most optometry students come to the program with a biological sciences background implies that educating these students require elucidation of "real-world" applications and clinical relevance to hold their interest. Even though the trend in optometric education in the past few years is to put more emphasis on biological sciences due to the increased scope of practice of the optometrist, optics still continues to play a major role in the training and career of an optometrist, especially with the advent of new technologies in treating low vision, measurement and correction of aberrations of the eye, etc.
\end{abstract}

\section{Introduction}

The field of Optometry probably began at the time when the first spectacles appeared. It is known that around 1300 there were spectacle manufacturing businesses in Italy, Germany and the Netherlands. The first bifocals were devised by Benjamin Franklin in the $18^{\text {th }}$ century in Philadelphia. See Rosen (1956) for a discussion of the historical origins of spectacles and optometry.

The first use of the term optometrist is thought to have been used by Landolt, a German, who contributed much to our knowledge of visual acuity (and devised a chart which is still in use) in 1886, to describe the fitting of glasses. This term became popular in the first two decades of the $20^{\text {th }}$ century. Before that optometrists were usually referred to as Opticians (a term that is still used today to describe people who make spectacles and dispense spectacles). In the $19^{\text {th }}$ century, there came a distinction between refracting opticians (the ones who test the eye and determine the correct spectacle prescription) and dispensing opticians. The refracting opticians became known as optometrists (Gregg, 1965).

Tenth International Topical Meeting on Education and Training in Optics and Photonics, edited by Marc Nantel, Proc. of SPIE Vol. 9665, 96651D · @ 2007 SPIE, OSA, IEEE, ICO doi: $10.1117 / 12.2207538$ 
Legal cases in the first half of the $20^{\text {th }}$ century ruled that optometry was separate from medicine. The origins of the fields differ both in the sciences from which they developed and in the shift of tradesmen into the professions. The scientific origins of optometry are in the optical sciences while medicine has its roots in the biological sciences. The professions developed amongst tradesmen - jewelers in the case of optometry (because they had the tools to work on spectacles) and barbers in the case of medicine (since they had the tools with which to do surgery!). The first American optometric licensing law was passed in the state of Minnesota in 1901, but by 1924 all states and the District of Columbia had optometry licensure laws. By comparison, the first medical licensure law in the US was passed in the late 1700s. However, it was not until 1895 that almost all states had their medical licensure boards. In addition, the diagnostic pharmaceutical agent law which allowed optometrists to use pharmacological methods to diagnose diseases of the eye was passed in Rhode Island in 1971 and the first therapeutic pharmaceutical agent law which allowed optometrists to prescribe certain medications for treatment of specific eye diseases was passed by West Virginia in 1976. Currently all fifty states have some form of DPA and TPA (including treatment of glaucoma). In Canada, the province of Ontario is currently in the process of approving a TPA law. Other laws being considered include the approval for optometrists to do refractive surgery procedures such as LASIK using a laser (in Oklahoma).

\section{Optometric Education}

Some of the first optometric schools were private schools. Amongst the existing optometric schools in the US, the Illinois College of Optometry can trace its roots to 1872 (predecessor schools; Northern Illinois College of Optometry and Otology, Needles Institute, Monroe College of Optometry and Chicago College of Optometry), while the New England College of Optometry can trace its roots to 1894 as the Kelin School of Optometry. Amongst university based schools, the oldest is the Ohio State University College of Optometry (Columbus, established in 1914), followed by the University of California at Berkeley. The first university based optometry program was established at Columbia University (New York) which opened in 1910 and closed in 1954. These university based optometry programs in general originated as a part of the Physics or Applied Physics curriculum. This is still true in many European optometry programs such as those in Portugal, Spain, Italy, etc. The first Canadian optometry program was established at the University of Waterloo in 1967. There are currently 17 schools and colleges of optometry in north America. The newest program in the US is the Optometry school at Western University of Health Sciences in Pomona, California which is to admit its first students in the fall of 2009.

Doctoral degrees for optometrists were awarded by various schools and the first Doctor of Optics degree was given by the Philadelphia Optics College (precursor to today's Pennsylvania College of Optometry) to optometry graduates in 1885 . Before the nineteen twenties, optometrists generally avoided using the term "doctor' but this gradually changed in the ensuing decades. Currently all north American 
institutions award an OD (Doctor of Optometry) degree while in other countries such as the UK, India, Australia, New Zealand and south Africa, only a bachelor's degree is given (B.Sc. in Optometry). In 1950, all ten of the optometry schools in existence at that time in the US required five years of study past high school. All private schools offered the OD degree. The Ohio State University, University of California and Indiana University (Bloomington), did not offer the OD degree until switching to a six year preoptometry and optometry curriculum. Berkeley, for example, did not graduate its first OD class until 1970. A more comprehensive review can be found in Woodruff (2001; see also Borish, 2001).

Currently, most students admitted to optometry programs in the US have an undergraduate (bachelor's) degree usually majoring in the biological sciences. Pre-requirements for admission include at least one year of college biology, general chemistry, general physics (with laboratories), as well as a year of college math for all optometric institutions. Other requirements vary depending on the school. Specific information about student profiles, enrollment, pre-requirements, etc. can be found in the Association of Schools and Colleges of Optometry web site (ASCO 2007).

\section{Optics in the Optometric Curriculum}

As noted earlier, optics being the historical basis of optometry, plays a major role in the education of an optometrist. The student of optometry is trained in various aspects of optics. These can be classified as : geometric, physical, ophthalmic and visual optics. This classification was done using the optics content outline for the National Board of Examiners in Optometry (NBEO), the major licensing exam for the optometrists (NBEO 2007). The website for NBEO gives a detailed listing of the areas covered in the optics section of the exam. This exam tests the minimum required knowledge/proficiency of a new entrant to the field. Sheedy et al (2006) has head of a special interest group of optometric educators at ASCO surveyed and analyzed the curriculum content. Figures 1 and 2 are from their survey. Because of difficulties in equating credit hours across institutions and differences between quarter and semester hours, actual instructional clock hours were used as the unit of measure. The mean (plus/minus SD) number of clock hours for lecture and laboratory are 202.7(27.0) and 102.7(33.7). Although there is variance in the number of lecture hours and how they are allocated across the institutions, it is small relative to the variance in laboratory hours. The number of laboratory hours of instructions in total and by optics category is quite small at several institutions. For example, at the University of Waterloo, there is no laboratory requirement for Physical Optics. Here, the results of the survey for clinical rotations (optical dispensing) is not included. 


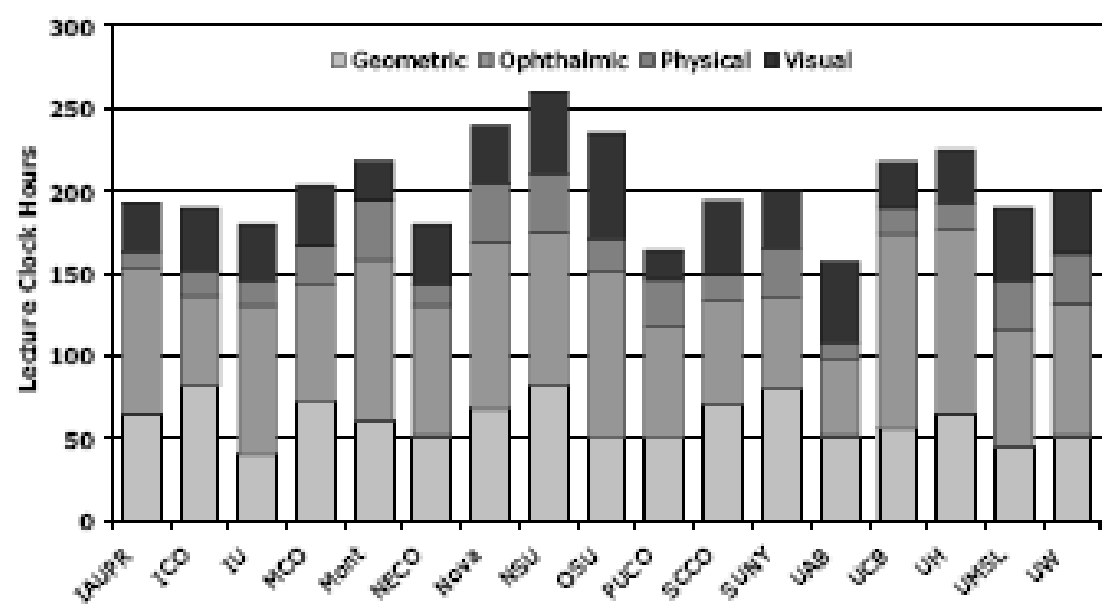

Figure 1. Clock hours of lecture in 4 areas of optics at 17 schools and colleges of optometry.

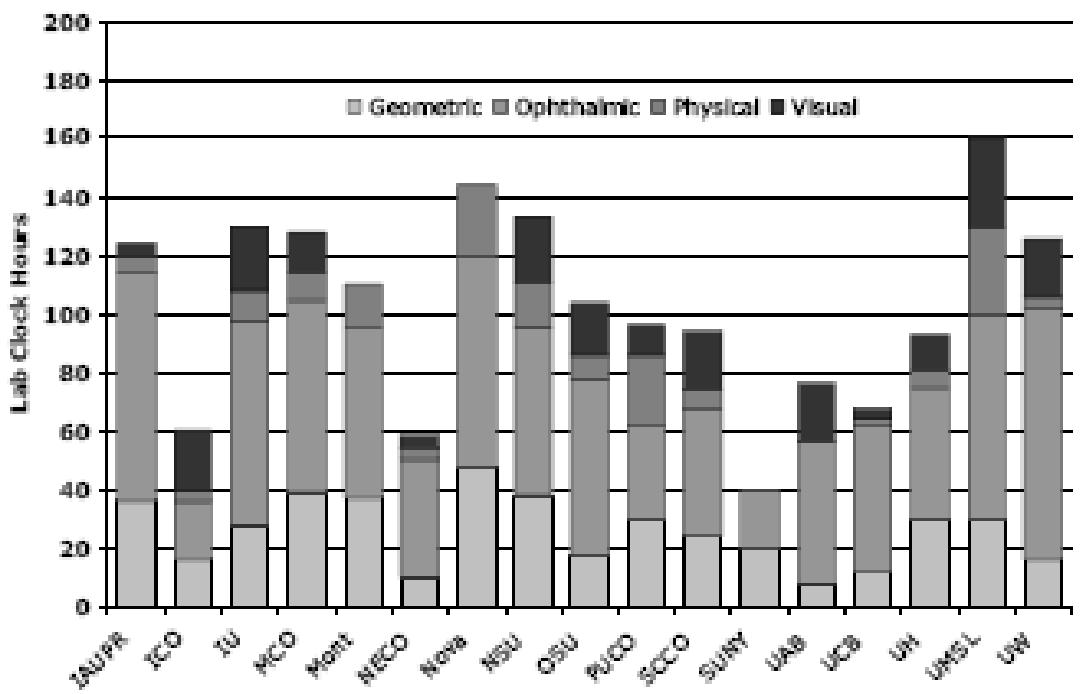

Figure 2. Clock hours of laboratory instruction in 4 areas of optics at 17 schools and colleges of optometry.

Given the amount of optics in the curriculum and the fact that the students are squeezed for time due to completing needs in the biological sciences curriculum, as a result of the expanding scope of clinical practice of the optometrist, students question the need for learning, for example, physical optics. It should be noted that in addition to biological sciences (including histology, microbiology, biochemistry, pharmacology, disease, etc), students also have to learn optometric jurisprudence, perceptual science, statistics and epidemiology, medical ethics, environmental vision and so forth. This brings about the question of importance of the quality and quantity of optics which is taught in the first year of the OD curriculum. In order to address this, there is the need to address the question of relevance. This brings out 
the requirement that the instructor has to show why the students need to understand basic optical principles by bringing up examples from the clinic -i.e., real world examples. Unfortunately there aren't many good text books that addresses this issue. The book by Pedrotti and Pedrotti (1998) attempts to deal with this by giving some examples, but far more is required. Mention should also be made of the book by Keating (2002) who is a professor in an Optometry school and was educated as a physicist. However, this book is considered "hard" and is used in only one school to the best of my knowledge. In my own teaching over the years, I have tried to do so. Examples will include in a discussion of say, total internal reflection, how it is used in gonioscopy in viewing the so-called angle of the anterior chamber, in fiber optics the fact that the incident light is trapped and sent to the sites of absorption by the pigment molecules in the photoreceptor as a waveguide, how chromatic aberration is used in the bichrome/duochrome test, resolution criteria applied to vision test charts, modulation transfer functions to the contrast sensitivity function of the human eye and its imaging performance, telescopes as applied to low-vision observers, thin film interference applied to anti-reflection coatings in spectacles, lasers and their applications in ophthalmic surgery etc..

Recent advances in technology such as aberration correction using Hartmann-Schack aberrometry and the use of adaptive optics(Porter et al 2007), excimer laser use in refractive surgery (Macrae et al 2001), polarimetric methods to examine the retina (Weinreb et al., 2002), etc. require that the future optometrist be intellectually equipped with the necessary optical physics and engineering knowledge to better utilize these advances for both diagnostic and therapeutic use. As optics educators it is up to us to not only deliver that information, but also do it in such a manner as to make it relevant and interesting to the studies and concerns of student optometrists.

\section{References}

ASCO - Association of Schools and Colleges of Optometry, www.opted.org/info_profile.cfm, 2007

Borish, I. Optometry: It's heritage and its future, Indiana J. Optom., 4:23-31, 2001.

Gregg, JR. The Story of Optometry, Ronald Press, NY, 1965.

Keating, MP. Geometric, Physical and Visual Optics, second edition, Butterworth-Heinemann, Woburn, MA, 2002.

MacRae, SM., Krueger, RR, and Applegate, RA. Eds., Customized corneal Ablation: the Quest for Super Vision, SLACK, Thorofare, NJ., 2001.

NBEO- National Board of Examiners in Optometry, www.optometry.org/pdf/contents/Optics.pdf, 2007

Pedrotti, LS., and Pedrotti, FL. Optics and Vision, Prentice Hall, Upper Saddle River, NJ, 1998.

Porter, J., Queener, H., Lin, J., Thorn, K and Awwal, A. Adaptive Optics for Vision Science, Wiley, NY, 2007.

Rosen, E. The invention of spectacles, J. Hist. Med. Allied Sci., 11:13-46, 183-218, 1956.

Sheedy, J. Optical curricula in optometry schools and colleges - are we properly preparing students for private practice? In: Mopane 2006: International Conference on Visual Optics, ed. A. Rubin, Optometric Science Research group, Dept. of Optometry, University of Johannesburg, South Africa, www.uj.ac.za/optometry/documents/Sheedy_2.pdf

Weinreb, RB., Bowd, C., Zangwell, LM. Glaucoma detection using scanning laser polarimetry with variable corneal polarization compensation, Arch. Ophthalmology, 120:218-224, 2002.

Woodruff, CE. The evolution of optometric education in America, J. American Optom. Associ., 72:779-786, 2001. 